\title{
Pathology of Hereditary Breast and Ovarian Cancer
}

\author{
Anjelica Hodgson ${ }^{1}$ and Gulisa Turashvili ${ }^{1,2 *}$ \\ 1 Department of Laboratory Medicine and Pathobiology, University of Toronto, Toronto, ON, Canada, ${ }^{2}$ Department \\ of Pathology and Laboratory Medicine, Mount Sinai Hospital, Toronto, ON, Canada
}

Hereditary breast and ovarian cancer (HBOC) syndrome is most commonly characterized by deleterious germline mutations in BRCA1 and BRCA2. HBOC patients are prone to the development of malignant neoplasms in multiple organs including the breast, ovary, and fallopian tube. From a pathological perspective, a number of morphological features have been described in BRCA-associated breast and tuboovarian cancers. For example, breast cancers diagnosed in BRCA1-mutation carriers are frequently of a high Nottingham grade and display medullary morphology and a triple-negative and/or a basal-like immunophenotype. In contrast, breast cancers in BRCA2-mutation carriers are similar to sporadic luminal-type tumors that are positive

OPEN ACCESS

Edited by: Raquel Nunes, Johns Hopkins University, United States

Reviewed by:

Sophia H. L. George, University of Miami, United States

Tricia Murdock,

The Johns Hopkins Hospital, Johns

Hopkins Medicine, United States

*Correspondence:

Gulisa Turashvil

gulisa.turashvili@sinaihealth.ca; gulisa.turashvili@gmail.com

Specialty section: This article was submitted to Women's Cancer, a section of the journal Frontiers in Oncology

Received: 25 March 2020 Accepted: 01 September 2020 Published: 29 September 2020

Citation:

Hodgson A and Turashvili $G$ (2020) Pathology of Hereditary Breast and Ovarian Cancer.

Front. Oncol. 10:531790. doi: 10.3389/fonc.2020.531790 for hormone receptors and lack expression of human epidermal growth factor receptor 2. Cancers arising in the fallopian tube and ovary are almost exclusively of a highgrade serous histotype with frequent Solid, pseudo-Endometrioid, and Transitional cell carcinoma-like morphology ("SET features"), marked nuclear atypia, high mitotic index, abundant tumor infiltrating lymphocytes, and necrosis. In addition, pushing or infiltrative micropapillary patterns of invasion have been described in BRCA-associated metastases of tubo-ovarian high-grade serous carcinomas. Besides BRCA1 and $B R C A 2$ mutations, alterations in a number of other homologous recombination genes with moderate penetrance, including PALB2, RAD51C, RAD51D, BRIP1, and others, have also been described in HBOC patients with varying frequency; however, distinct morphological characteristics of these tumors have not been well characterized to date. In this review, the above pathological features are discussed in detail and a focus is placed on how accurate pathologic interpretation plays an important role in allowing HBOC patients to receive the best possible management.

Keywords: BRCA, hereditary breast cancer, hereditary tubo-ovarian cancer, high-grade serous carcinoma, triplenegative breast cancer

\section{INTRODUCTION}

Hereditary breast and ovarian cancer (HBOC) is a genetic tumor syndrome most commonly caused by germline deleterious mutations in BRCA1 and BRCA2. The BRCA1 and BRCA2 tumor suppressor genes (chromosome 17q21 and 13q12.3, respectively) (1-6) encode for proteins involved in DNA double strand break repair by homologous recombination, one of the critical maintenance mechanisms of DNA integrity (7). In order to complete this function, the BRCA proteins interact with a host of other molecules which together form a protein complex; without 
a functional BRCA complex, the cell relies on alternative mechanisms for DNA repair, some of which are error prone and may further contribute to the development of genetic aberrations (8). Because of this phenomenon, HBOC patients with germline $B R C A 1$ and BRCA2 mutations have an increased risk for the development of a number of neoplasms, particularly those arising in the breast as well as ovary and fallopian tube (9) (hereby referred to as "tubo-ovarian cancer").

In the general population, the risk for the development of breast and tubo-ovarian cancer is approximately $10-15 \%$ and $1-2 \%$, respectively. In $B R C A 1$ and $B R C A 2$ mutation carriers, the risk increases to approximately $45-65 \%$ and $20-50 \%$, respectively (10-14). Germline mutations in other homologous recombination genes including $B A R D 1, B R I P 1, P A L B 2, R A D 51 C$, $R A D 51 D$, and others (all encoding proteins involved in BRCA protein stability and/or function), have also been identified to varying degrees in breast and tubo-ovarian cancer patients. Studies evaluating the lifetime risk of disease development in these patients have estimated a range of at least $15-35 \%$ for breast cancer $(15,16)$ and $5-10 \%$ for tubo-ovarian cancer $(17-$ 20). Mutations in some of these genes impart an increased risk for either breast or tubo-ovarian cancer with minimal to no increased risk for the development of the other tumor type (i.e., increased risk of breast cancer without risk of tubo-ovarian cancer, and vice versa) (21-24). For example, BRIP1, RAD51C, and RAD51D mutation carriers have an increased risk for tubo-ovarian cancer, while there is insufficient evidence for an increased risk for breast cancer development. In contrast, BARD1 and PALB2 mutation carriers have an increased risk for breast cancer development without an associated increased risk for tubo-ovarian cancer (25).

A number of morphological features perceived at the time of microscopic examination have been described in BRCA-related breast and tubo-ovarian cancers, and the discussion of these characteristic features and their clinical relevance will be the main topic of this review. In addition, tumor and germline genetic testing will also be discussed.

\section{HBOC-ASSOCIATED BREAST CANCER}

Breast carcinoma is the most common malignancy arising in female patients with $\mathrm{HBOC}$ as a result of germline $B R C A 1 / 2$ mutations. For risk reduction, bilateral mastectomy is recommended for all $B R C A 1 / 2$ mutation carriers (26). From a pathological perspective, BRCA1 and BRCA2-associated breast tumors have been shown to differ on both morphological and molecular levels (Table 1). Furthermore, BRCA1-associated tumors tend to be more difficult to visualize on mammographic studies compared to BRCA2-associated tumors which more commonly present with microcalcifications and/or isolated ductal carcinoma in situ (27).

\section{BRCA1-Associated Breast Cancer}

Morphologically, BRCA1-associated breast carcinomas are most commonly a high-grade invasive ductal carcinoma of no special type and display minimal if any tubule or glandular formation, markedly pleomorphic nuclei (significant variation in size and
TABLE 1 | Morphological and molecular features of BRCA1 and BRCA2-associated breast cancer.

\begin{tabular}{lll}
\hline Morphological features & BRCA1 & BRCA2 \\
\hline Tubule formation & $\begin{array}{l}\text { Minimal to none, } \\
\text { "medullary" solid growth }\end{array}$ & Abundant \\
Nuclear grade & High & $\begin{array}{l}\text { Variable, usually low to } \\
\text { intermediate }\end{array}$ \\
Mitotic rate & High & $\begin{array}{l}\text { Variable } \\
\text { Overall Nottingham grade } \\
\text { Intrinsic molecular }\end{array}$ \\
$\begin{array}{l}\text { Hubgroup } \\
\text { Biomarker profile }\end{array}$ & Basal-like & Variable, usually grade 1 or 2 \\
& ER-, PR-, HER2- & Luminal-like (luminal A) \\
\end{tabular}

ER, estrogen receptor; PR, progesterone receptor; and HER2, human epidermal growth factor receptor 2 .

shape), vesicular chromatin, prominent nucleoli, and high mitotic activity. A "medullary" appearance with a sheet-like proliferation of tumor cells, pushing borders, necrosis, and prominent peri- and intra-tumoral lymphocytes has also been described (Figure 1). Of note, classical criteria for medullary carcinoma of the breast include syncytial architecture composing $>75 \%$ of the tumor mass, histological circumscription with pushing margins, lack of tubular differentiation and in situ carcinoma, a prominent and diffuse lymphocytic infiltrate, and round tumor cells with abundant cytoplasm and pleomorphic high-grade vesicular nuclei containing one or several nucleoli $(28,29)$. Given that these diagnostic criteria are difficult to apply and lead to high interobserver variability, the World Health Organization (WHO) proposes the term "invasive carcinoma of no special type with medullary pattern" to describe a tumor exhibiting some or all of the above characteristics (30). From a molecular perspective, the majority of these BRCA1-associated breast tumors fall into the "basal-like" subtype of breast cancer, one of the four common intrinsic molecular subtypes (31). "Basal-like" tumors are characterized by overexpression of genes associated with basal epithelium and proliferation and minimal to no expression of genes associated with estrogen receptor (ER) and human epidermal growth factor receptor 2 (HER2). This gene expression profile is reflected in the immunohistochemical expression of basal markers including cytokeratin 5/6 and epidermal growth factor receptor (EGFR), in addition to lack of expression of ER and progesterone receptor (PR) as well as HER2 (27, 32-35). Metaplastic carcinomas have also been reported in BRCA1 mutations carriers $(36,37)$.

\section{BRCA2-Associated Breast Cancer}

In contrast to BRCA1-associated breast cancers, BRCA2associated tumors are very similar to sporadically-occurring "luminal-type" tumors (31). This group comprises the most common of the intrinsic molecular subtypes of breast cancer (luminal A) and is characterized by variable expression of genes typically expressed in luminal breast epithelium and those associated with ER (31). Morphologically, these tumors are most commonly invasive ductal carcinoma of no special type of variable grade and do not appear to have a specific morphology, although lobular carcinomas have been 


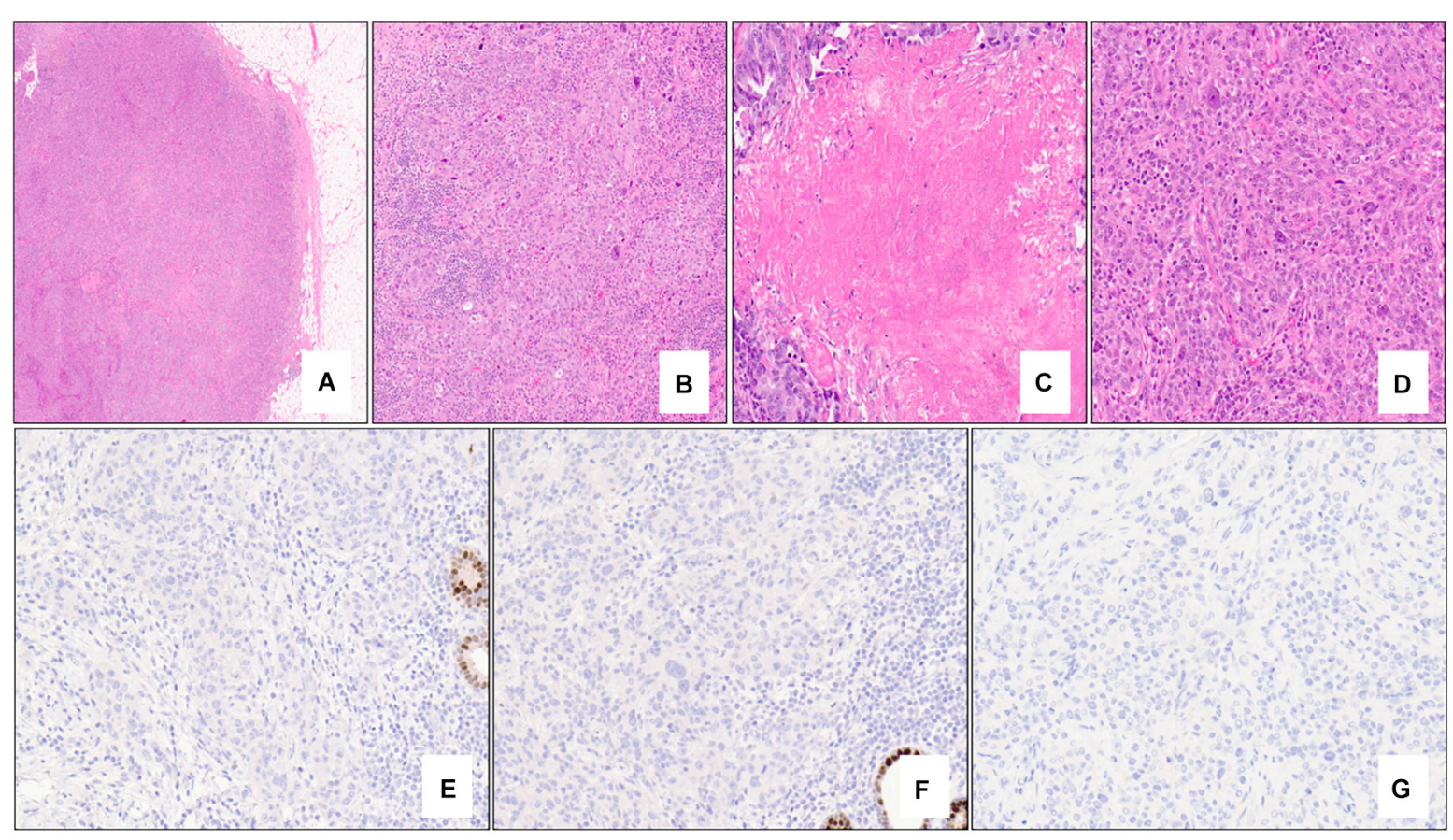

FIGURE 1 | Nottingham grade 3 invasive ductal carcinoma (no special type) of the breast associated with BRCA1 germline mutation and "triple-negative" biomarker profile. The tumor exhibits solid architecture and pushing border (A - 2x mag), prominent intra-tumoral lymphocytes (B - 10x mag), large areas of necrosis (C - 15x mag), and high-grade nuclear atypia with prominent nucleoli (D - 20x mag). The tumor is triple-negative lacking expression of estrogen receptor (E - 20x mag), progesterone receptor (F - 20x mag), and HER2 (G - 20x mag). Note the positive internal control cells (benign terminal duct lobular units) in (E,F).

(A-D) hematoxylin-eosin stain; (E-G) immunohistochemistry.

reported to be more likely related to BRCA2 mutations (32). Immunohistochemically, $B R C A 2$-associated tumors are typically positive for low molecular weight keratins, ER and PR and lack HER2 protein overexpression (38) (Figure 2).

\section{Non-BRCA-Associated Breast Cancer}

To date, no specific morphological features have been described in tumors associated with mutations in non-BRCA genes which impart increased risk for breast cancer development.

\section{HBOC-ASSOCIATED TUBO-OVARIAN CANCER}

\section{General Tumor Morphology}

Germline BRCA1/2 mutations are found in approximately 15\% of women with ovarian epithelial neoplasms, the most common tubo-ovarian tumor subtype (39). The hallmark histopathologic diagnosis of HBOC-related tubo-ovarian cancer due to $B R C A$ mutations is that of high-grade serous carcinoma (40-42), and the frequency of BRCA1 and BRCA2 germline mutations increases to approximately $25 \%$ in patients diagnosed with these neoplasms (43-45). In addition to high-grade serous carcinoma, other ovarian tumor histotypes including those with endometrioid, mucinous and clear cell differentiation (and others) have also been described to varying degrees in $B R C A$-associated cohorts $(32,33,39,46,47)$, although some of these studies did not have central review of all pathological specimens (48).

Morphologically, classical high-grade serous carcinoma shows expansile and infiltrative growth of glands and papillae with slit-like spaces. Tumor nuclei are generally enlarged and irregular with prominent nucleoli and brisk mitoses, including atypical forms (Figure 3A). Immunohistochemically, highgrade serous carcinomas express p53 in an aberrant pattern (most commonly either nuclear overexpression or complete absence of expression, and less commonly cytoplasmic pattern expression) (Figures 3B-D), in addition to CK7, PAX8, and WT-1. ER (and much less commonly PR) usually shows diffuse and strong expression, although staining may be variable in some cases. P16 expression is typically diffuse, strong and block-like.

\section{Specific Tumor Characteristics}

A variety of specific morphological characteristics have been described in the context of $B R C A$-associated high-grade serous carcinoma (Table 2). Fujiwara et al. showed that tuboovarian carcinomas in a cohort of BRCA1 germline mutation carriers tended to exhibit high-grade and serous/undifferentiated histology, prominent tumor infiltrating lymphocytes (TILs), marked nuclear atypia with giant/bizarre forms, and abundant mitotic figures; these features had a negative predictive value of $>94 \%$ and a positive predictive value of $21 \%$ for $B R C A 1$ germline mutation status (49). Soslow et al. studied tumors 


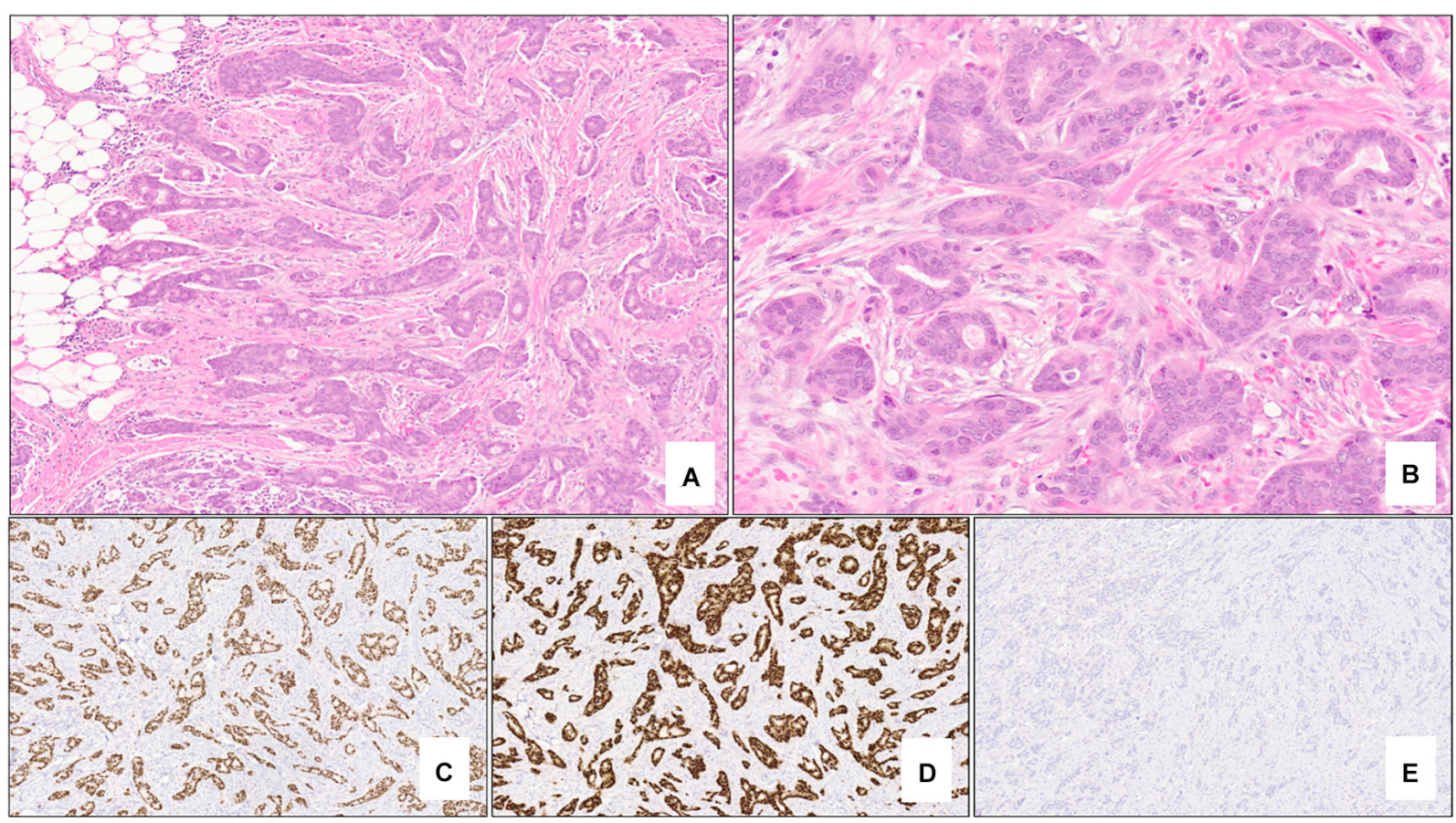

FIGURE 2 | Nottingham grade 2 invasive ductal carcinoma (no special type) of the breast associated with BRCA2 germline mutation. The tumor shows $>75 \%$ tubule formation (A - 5x mag) with moderate nuclear pleomorphism and inconspicuous mitotic activity (B - 20x mag). Almost 100\% of the neoplastic cells are strongly positive for estrogen receptor $(\mathbf{C}-5 x$ mag) and progesterone receptor (D - 5x mag), and negative (score 0) for HER2 protein overexpression (E - 5x mag). (A,B) hematoxylin-eosin stain; (C-E) immunohistochemistry.
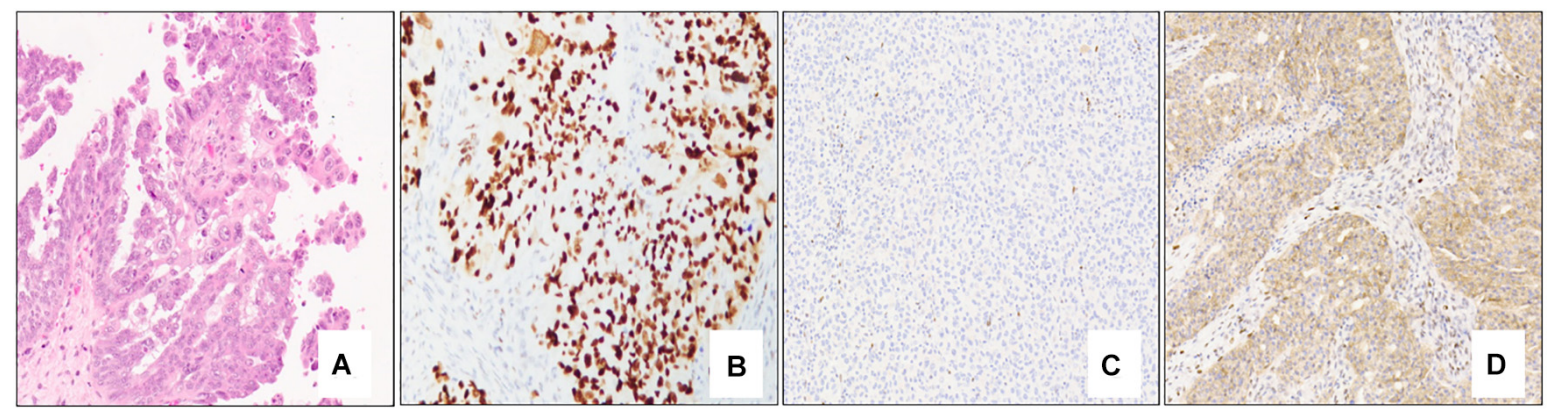

FIGURE 3 | Classical high-grade serous carcinoma composed mostly of papillae lined by atypical epithelial cells with irregular and pleomorphic nuclei and prominent nucleoli (A - 10x mag). Immunohistochemical staining patterns of p53 in high-grade serous carcinoma: Strong, diffuse nuclear staining (B - 10x mag), complete absence of staining/null pattern (C - 10x mag), and cytoplasmic staining (D - 10x mag); note the positive internal control (lymphocytes) in (C). (A) hematoxylin-eosin stain; (B-D) immunohistochemistry.

from patients with germline $B R C A 1 / 2$ mutations in addition to tumors with somatic BRCA1/2 mutation or promoter hypermethylation and found that BRCA1-associated highgrade serous carcinomas exhibit high mitotic rates, increased TILs, geographic/comedo-type necrosis, and non-traditional architectural patterns including Solid, pseudo-Endometrioid, and Transitional-like (SET) features. BRCA2-mutated tumors also had SET features but tended to have a relative deficiency of TILs and necrosis (42). Examples of SET features are shown in Figures 4A-F; note the sheet-like growth of the solid pattern, the glandular spaces in the pseudo-endometrioid pattern, and broad and multi-layered papillary-like structures of the transitionallike pattern.

Prior to the recognition of SET features in high-grade serous carcinoma, tumors exhibiting these morphological findings were often misdiagnosed as high-grade endometrioid, transitional cell, or undifferentiated carcinomas. In a more recent study, Ritterhouse et al. confirmed that tumors with homologous recombination deficiency, including those diagnosed in BRCA1 and BRCA2 mutation carriers, are six times more likely to exhibit non-classical (SET or ambiguous) features of high-grade serous carcinoma (50). 
TABLE 2 | Morphological features of BRCA1 and BRCA2 associated high-grade serous carcinoma.

\begin{tabular}{|c|c|}
\hline Morphological features & BRCA2 \\
\hline Architecture & Frequent SET morphology \\
\hline Nuclear atypia & Marked \\
\hline Necrosis & Relatively deficient \\
\hline TILS & Relatively deficient \\
\hline Morphology of metastases & $\begin{array}{l}\text { Pushing invasion or infiltrative invasion composed } \\
\text { exclusively of micropapillae }\end{array}$ \\
\hline Immunophenotype & $\begin{array}{c}\mathrm{CK} 7+\text {, PAX8 +, WT-1 +, ER +, PR +/-, aberrant } \\
\text { expression pattern of p53, and diffuse p16 }\end{array}$ \\
\hline
\end{tabular}

Although the aforementioned features are associated with BRCA-mutated tumors, the data to date have not been able to demonstrate differences to accurately distinguish tumors associated with germline mutations versus somatic mutations and $B R C A$ promoter methylation based on morphology alone. As such, confirmatory genetic testing is necessary. However, identification of morphological features associated with $B R C A 1 / 2$ is useful for clinical guidance and potential genetic screening.

In addition to morphological features identified at the primary tumor site, specific architectural patterns (metastatic deposits with rounded and pushing contours/"medullary-like" invasion or infiltrative invasion composed exclusively of micropapillae) identified at metastatic sites have also been found to be highly concordant with $B R C A 1 / 2$ mutation status and display a high level of agreement among observers (kappa >0.9) (51) (Figures 4G-I). Cases which displayed those features at metastatic sites most commonly also exhibited SET features in both the metastatic and primary tumors. Distinction between these two patterns appears to be prognostically relevant as an infiltrative micropapillary pattern has been more commonly identified in metastatic tumor foci from patients who suffered recurrence or death from disease, compared to those with

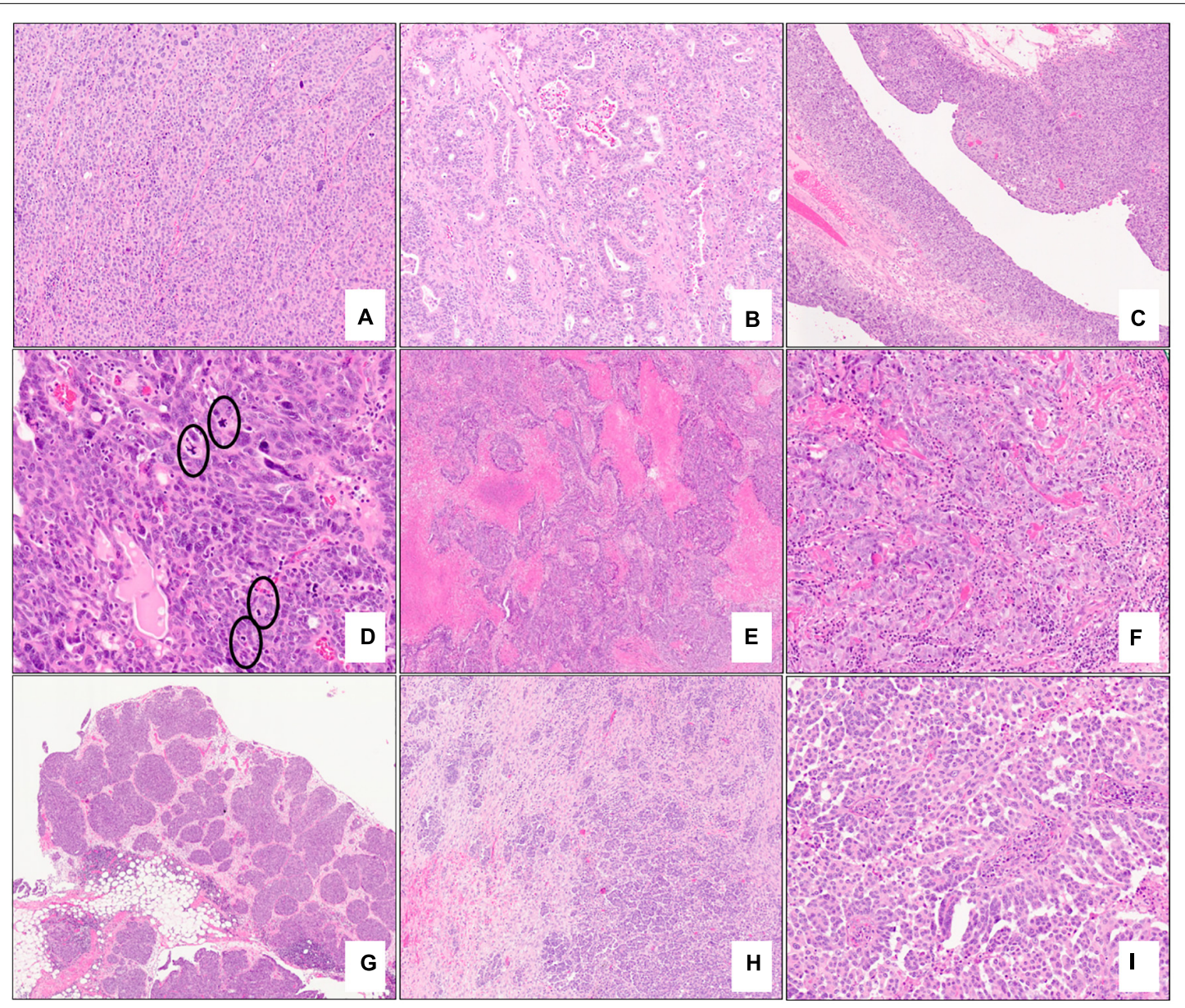

FIGURE 4 | Examples of morphologic features of primary and metastatic high-grade serous carcinoma with BRCA mutations. Solid (A - 10x mag), pseudo-endometrioid (B - 10x mag), and transitional cell carcinoma-like (C - 5x mag) architectural patterns; note features reminiscent of papillary urothelial carcinoma in (C). Brisk mitotic activity (D - 20x mag), geographic necrosis (E - 2x mag), and increased tumor infiltrating lymphocytes (F - 10x mag) are present. Omental involvement by BRCA-associated high-grade serous carcinoma. A well-circumscribed tumor nodule with a rounded edge and pushing border (G - $2 x)$ and an infiltrative focus composed exclusively of micropapillae (H - 5x mag, I - 15x mag). (A-I) hematoxylin-eosin stain. 
pushing pattern metastases (52). Interestingly, it has been hypothesized that metastatic tumor architecture may influence the ease of resection of these deposits and thus may contribute to surgeons' ability to achieve optimal tumor debulking in these patients $(51,53)$.

Interestingly, loss of BRCA1 protein expression by immunohistochemistry has been shown to correlate with $B R C A 1$ mutation status or BRCA1 promoter hypermethylation with negative predictive values ranging from $95 \%$ to $100 \%$ $(54,55)$. Despite these findings, this technique is not used in routine clinical practice, likely because of a number of limitations including internal control issues, the requirement for nuanced interpretation, and because at least some BRCA1 clones are not helpful in detecting mutations in certain parts of the gene $(54,56)$. Immunohistochemistry for the assessment of BRCA2 expression also exists; however, studies to date which have evaluated its use appear to be heterogeneous and have shown mixed results (57).

\section{Role of the Fallopian Tube in the Pathogenesis of High-Grade Serous Carcinoma}

It is now widely accepted that the majority of high-grade serous carcinomas arise from fallopian tube epithelium (5860). Serous tubal intraepithelial carcinoma (STIC) has been recognized as an early form/precursor of high-grade serous carcinoma $(61,62)$. Approximately $40-60 \%$ of all women with high-grade serous carcinoma will harbor a STIC lesion (63, 64). STICs are most commonly identified in the fimbriated end of the fallopian tube near the tubal-peritoneal junction. Although precursor lesions in the fallopian tube had been described prior to the implementation of risk reducing bilateral salpingo-oophorectomy (rrBSO), the possible relationship with ovarian high-grade serous carcinoma was only noted after implementation in the management of patients with germline BRCA1/2 mutations. Approximately 5-10\% of patients with $B R C A 1 / 2$ mutations who undergo $\mathrm{rrBSO}$ will harbor some form of early serous neoplasia (discussed below), most commonly STIC $(60,65,66)$. It should be noted that rrBSO is recommended by multiple guidelines for BRCA1/2 mutation carriers between the ages of 35 to 40 (or once childbearing is complete or 10 years younger than the age of the youngest first degree relative diagnosed with tubo-ovarian cancer). The age of prophylactic surgery may be delayed until 40 to 45 years of age in some BRCA2 carriers in addition to RAD51C, RAD51D, and BRIP1 mutation carriers $(26,67)$. Salpingectomy only followed by interval oophorectomy is another therapeutic alternative being actively investigated (68).

Microscopically, STICs exhibit multilayered epithelium with minimal to mild tufting and stratification, loss of polarity, hyperchromatic and often pleomorphic nuclei, and prominent nucleoli; cilia are absent, and mitotic figures and apoptotic bodies are usually seen (69). A morphological and immunohistochemical algorithm was proposed in 2011 and validated in 2012 for standardization of the classification of STIC, according to which STICs should exhibit an elevated
Ki-67 proliferation index (>10\%) and aberrant expression of p53 protein (overexpressed in $>75 \%$ of cells or completely absent/null-pattern) (Figure 5) (69, 70). Precursor lesions that do not meet the morphological and/or immunohistochemical criteria for STIC are categorized as serous tubal intraepithelial lesion (STIL) or p53 signature (70). STIL may be diagnosed in a number of different scenarios: (a) tubal epithelium with unequivocal features of STIC and aberrant p53 expression and a low $(<10 \%) \mathrm{Ki}-67$ proliferation index, or wild-type p53 expression and high (>10\%) Ki-67 index, or wild-type p53 expression and low (<10\%) Ki-67 index; (b) atypical tubal epithelium suspicious for STIC and either aberrant p53 expression and low $(<10 \%)$ proliferation index, or wild-type p53 expression and high (>10\%) Ki-67 index; and (c) morphologically normal epithelium with aberrant $\mathrm{p} 53$ expression and a high (>10\%) Ki-67 index. P53 signature is defined by morphologically normal (or near normal) epithelium with aberrant p53 expression and a low $(<10 \%)$ Ki-67 proliferation index. These lesions have been shown to share TP53 mutations with adjacent invasive carcinomas $(64,71,72)$.

An alternate classification scheme exists which does not rely on Ki-67 proliferation index and which rather focuses on epithelial atypia combined with aberrant p53 immunohistochemical staining. Some forms of benign epithelial atypia (i.e., secretory or stem cell outgrowths, i.e., SCOUTs) are discrete proliferations which may lose cilia but lack aberrant p53 immunohistochemical expression. When aberrant p53 staining is detected in a discretely altered epithelium lacking cilia, the lesion may be classified one of three ways: (a) as a STIC when a loss of polarity is detected, (b) as a serous tubal epithelial proliferation/lesion of uncertain significance when polarity is retained but atypia is present, or (c) benign serous tubal intraepithelial proliferation/p53 signature when polarity is retained and atypia is absent (73).

It should be noted that there is still considerable work being done with regard to the origin of tubo-ovarian high-grade serous carcinoma as in some patients (especially those diagnosed with high stage tumors), no evident STIC is ever identified. In particular, tumors exhibiting SET morphology have a lower level of correlation with the presence of STIC compared to tumors with classical morphology $(74,75)$. This finding suggests that tumors with SET morphology may derive from a number of different mechanisms including rapid overgrowth of STIC or an alternate tubal precursor lesion (75). This has led to some investigators to question whether the carcinogenic sequence leading to high-grade serous carcinoma is more complex (76). Currently, assignment of the fallopian tube as a primary site is based on the finding of STIC, invasive mucosal carcinoma with or without STIC, or if the fallopian tube is partially or entirely incorporated into tubo-ovarian mass. Tumors lacking STIC or invasive mucosal carcinoma in either fallopian tube in presence of macroscopic or microscopic ovarian involvement can be classified as primary ovarian regardless of presence and size of peritoneal disease (77). High-grade serous carcinoma can be classified as primary peritoneal if both fallopian tubes and ovaries have been examined entirely, and are macroscopically and microscopically normal. 


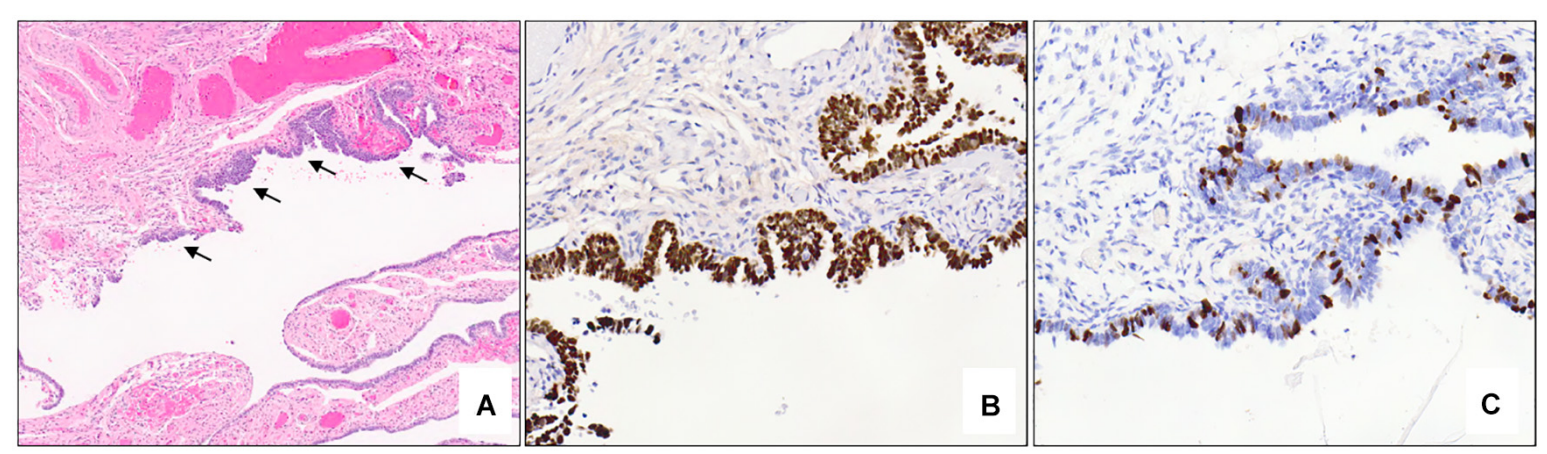

FIGURE 5 | Serous tubal intraepithelial carcinoma. Low power examination of the fimbriated end of the fallopian tube shows an atypical focus (black arrows) which appears darker and crowded compared to the adjacent benign epithelium (A - 5x mag). Immunohistochemical stains show aberrant expression of p53 with strong, diffuse nuclear staining (B - 10x mag) and an elevated (>10\%) Ki-67 proliferation index (C - 10x mag) in the atypical area. (A) hematoxylin-eosin stain,

(B,C) immunohistochemistry.

\section{Non-BRCA-Associated Tubo-Ovarian Cancer}

Similar to breast cancers associated with mutations of non$B R C A$ genes involved in homologous recombination, limited data currently exists which definitively describes any specific morphological features associated with these tumors.

\section{ADDITIONAL TUMOR CONSIDERATIONS}

Although the prototypical female cancers associated with HBOC are those arising in the breast and ovary/fallopian tube/peritoneum, recent work suggests that some endometrial carcinomas may be associated with underlying BRCA alterations. de Jonge et al. have shown homologous recombination deficiency in $24 \%$ of endometrial cancers, all with non-endometrioid morphology (78). In addition, endometrial carcinomas in germline BRCA1 or BRCA2 mutation carriers have also been reported to be of non-endometrioid subtype in 58\% of cases and grade 3 histology in $79 \%$ of cases, and most commonly fall into the TP53-mutated molecular subgroup defined by The Cancer Genome Atlas Research Network (TCGA) in 92\% of cases (79). Overall, these interesting findings warrant additional studies to establish whether endometrial cancer patients may benefit from treatment targeting homologous recombination deficiency. The findings also raise important potential consequences from counseling/surveillance perspectives.

Besides malignancies arising in the breast and gynecological organs, an increased risk of other neoplasms, including pancreatic carcinoma, gastric carcinoma and cutaneous malignant melanoma (80-82), has been reported in HBOC patients, particularly in individuals with germline BRCA2 mutations. However, in contrast to the better characterized phenotype-genotype correlations in female breast and gynecological tumors discussed above, no particular BRCAassociated morphological features have been described in these tumors, to the best of our knowledge. Nevertheless, awareness of the potential association that these tumors may have with an underlying $B R C A$ mutation is very important, especially when they are identified in a patient without a known family history.

\section{CLINICAL IMPLICATIONS}

\section{Pathological Processing}

The concept that the many high-grade serous carcinomas arise from the fallopian tube has played a major role in driving the evolution of how prophylactic surgical specimens from HBOC patients are evaluated. Currently, it is standard practice to examine these specimens according to the SEE-FIM (Sectioning and Extensively Examining the Fimbriated end of the fallopian tube) protocol (60) which dictates that the distal $2 \mathrm{~cm}$ of each fimbriated end should be sectioned at $2 \mathrm{~mm}$ intervals along the long axis and entirely submitted for microscopic examination. The remainder of the fallopian tube is also to be sectioned at $2 \mathrm{~mm}$ intervals and entirely submitted, in addition to both ovaries (in the absence of any grossly evident lesion). The purpose of the SEE-FIM protocol is to maximally expose tubal fimbrial epithelium for microscopic evaluation, as STIC lesions are typically focal and not grossly evident.

\section{Treatment}

Importantly, the identification of an germline-associated $B R C A 1 / 2$-mutated tumor indicates not only an underlying germline defect (in the patient and perhaps also in her family members), but also implies certain important prognostic and treatment connotations. For example, mutations involving genes whose protein products are involved in homologous recombination have been shown to be associated with chemotherapeutic platinum sensitivity and improved survival in both breast and tubo-ovarian cancer patients $(46,50,83)$. Similarly, triple-negative breast cancer patients harboring defects in homologous recombination proteins have been shown to exhibit increased sensitivity to both platinum-based and standard chemotherapy regimens $(84,85)$, although the effect on prognosis is more complex (86). The underlying molecular 
abnormalities due to homologous recombination deficiency indicate that these malignancies can be treated with novel poly ADP-ribose polymerase (PARP) inhibitors which act to limit repair of single strand breaks (87) and thus lead to tumor cell death due to the overwhelming genetic instability (88). Recent studies have also shown that BRCA-deficient tumors have elevated expression levels of programmed cell death protein 1 (PD-1) and programmed cell death ligand 1 (PD-L1) in tumor-associated immune cells, indicating that checkpoint inhibitors may be useful in the treatment of $B R C A$-associated cancers (89-91).

\section{Genetic Testing}

Tumor and germline genetic testing is variably performed in patients affected by breast (92) and ovarian carcinomas (93). It has been shown that triaging women for genetic testing based on family history alone will miss up to $30 \%$ of affected individuals (94). Nevertheless, genetic testing for breast cancer patients is still largely based on family history risk (Table 3) (26). However, it has been suggested that all patients with breast cancer should undergo genetic testing in order to optimize treatment and improve survival, but also to mitigate risk for family members that are healthy mutation carriers (95).

For tubo-ovarian cancer, an approach driven by histological tumor features has been adopted in a number of institutions given the strong association between high-grade serous morphology and $B R C A 1 / 2$ mutations. It is generally recommended that every tubo-ovarian/primary peritoneal high-grade serous carcinoma be tested for at least somatic BRCA1/2 gene mutations, in addition to mutations in other high-risk genes (96). At some institutions, this testing is done reflexively once a diagnosis of high-grade serous carcinoma has been made. Diagnostic accuracy is therefore critical. Importantly, mutation testing should be done regardless of the presence or absence of the morphological features discussed above. Some organizations have recommended germline testing in all patients with invasive non-mucinous epithelial ovarian, fallopian tube or peritoneal cancers (i.e., not only high-grade serous carcinomas, but also endometrioid, clear cell, and seromucinous subtypes) (97-99). If tumor testing is undertaken and a mutation is identified, referral to genetic counseling for consideration of additional germline testing is necessary (if not already done) as a proportion of pathogenic mutations identified in tumor tissue will be of germline origin. A number of genetics referral models exist with each model having its advantages and disadvantages (100).

In the past, single gene testing was used for the purpose of assessing underlying mutations. However, the use of comprehensive multigene panel testing has become increasingly prevalent and has helped to identify additional patients with BRCA1/2 mutations as well as patients with mutations in other genes associated with an increased risk. Although a multigene testing approach provides advantages in terms of comprehensive assessment, cost and turnaround time, the goals of practical clinical utility and ease of interpretation should always be kept in mind (101, 102), in addition to the care that should be taken to ensure extensive and in-depth clinical and analytical validation (103).
TABLE 3 | Criteria for breast and/or ovarian cancer genetic assessment.

\begin{tabular}{|c|c|}
\hline Any individual (at any age): & $\begin{array}{l}\text { - With a known pathogenic or likely } \\
\text { pathogenic variant in a cancer susceptibility } \\
\text { gene within the family } \\
\text { - With a known pathogenic or likely } \\
\text { pathogenic variant in a cancer susceptibility } \\
\text { gene discovered on tumor testing }\end{array}$ \\
\hline $\begin{array}{l}\text { Any individual (at any age) who } \\
\text { develops the following: }\end{array}$ & $\begin{array}{l}\text { - Ovarian cancer } \\
\text { - Pancreatic cancer } \\
\text { - Metastatic prostate cancer } \\
\text { - Is of Ashkenazi Jewish ancestry and } \\
\text { develops breast cancer or high-grade } \\
\text { prostate cancer }\end{array}$ \\
\hline $\begin{array}{l}\text { Any individual with breast } \\
\text { cancer and the following: }\end{array}$ & $\begin{array}{l}\text { - Diagnosis is at } \leq 50 \text { years of age } \\
\text { - Development of a triple-negative cancer at } \\
\leq 60 \text { years of age } \\
\text { - Two separate breast cancers (either in the } \\
\text { same or contralateral breast, synchronous } \\
\text { or metachronous) } \\
\text { - } \geq 2 \text { close blood relatives diagnosed with } \\
\text { breast cancer at any age }\end{array}$ \\
\hline $\begin{array}{l}\text { Any individual with breast } \\
\text { cancer at any age and } \geq 1 \text { close } \\
\text { blood relative with the following: }\end{array}$ & $\begin{array}{l}\text { - A diagnosis of breast cancer at } \leq 50 \text { years } \\
\text { of age } \\
\text { - Ovarian cancer } \\
\text { - Male breast cancer } \\
\text { - Pancreatic cancer } \\
\text { - High-grade or metastatic prostate cancer }\end{array}$ \\
\hline $\begin{array}{l}\text { Any individual who does not } \\
\text { meet the above criteria but who } \\
\text { has a first or second degree } \\
\text { relative with any of the } \\
\text { following: }\end{array}$ & $\begin{array}{l}\text { - Diagnosis of breast cancer at } \leq 45 \text { years of } \\
\text { - Oge } \\
\text { - Marian cancer } \\
\text { - Pancreatic cancer } \\
\text { - Metastatic prostate cancer } \\
\text { - } \geq 2 \text { separate breast cancers in a single } \\
\text { individual } \\
\text { - } \geq 2 \text { individuals with breast cancer on the } \\
\text { same side of the family with at least one } \\
\text { diagnosed } \leq 50 \text { years of age }\end{array}$ \\
\hline
\end{tabular}

Any individual with a personal and/or family history on the same side of the family of $\geq 3$ of a variety of malignant neoplasms

A close blood relative includes a first, second, or third degree relative.

\section{CONCLUSION}

In this review, we have discussed the HBOC syndrome from a pathological perspective and have described specific characteristics of BRCA1 and BRCA2-associated breast and tubo-ovarian neoplasms. Pathologists play a critical role in the identification and triage of affected patients, particularly those without a known family history, as a number of morphological features associated with these BRCA-mutated tumors have been reproducibly described and are easily recognized. Accurate and timely pathological assessment and interpretation is critical given the implications for prognosis, therapy and genetic testing. Ongoing research will continue to refine our understanding of HBOC syndrome pathology, including how non-BRCA gene mutations affect tumor morphology, behavior and prognosis. In addition, our understanding will continue to develop regarding precursor lesions of high-grade serous carcinoma and other neoplasms arising in the context of the syndrome, including endometrial carcinoma and other non-gynecologic tract tumors. 


\section{DATA AVAILABILITY STATEMENT}

The original contributions presented in the study are included in the article/supplementary material, further inquiries can be directed to the corresponding author.

\section{REFERENCES}

1. Hall JM, Lee MK, Newman B, Morrow JE, Anderson LA, Huey B, et al. Linkage of early-onset familial breast cancer to chromosome 17q21. Science. (1990) 250:1684-9. doi: 10.1126/science.2270482

2. Friedman LS, Ostermeyer EA, Szabo CI, Dowd P, Lynch ED, Rowell SE, et al. Confirmation of BRCA1 by analysis of germline mutations linked to breast and ovarian cancer in ten families. Nat Genet. (1994) 8:399-404. doi: 10.1038/ng1294-399

3. Miki Y, Swensen J, Shattuck-Eidens D, Futreal PA, Harshman K, Tavtigian S, et al. A strong candidate for the breast and ovarian cancer susceptibility gene BRCA1. Science. (1994) 266:66-71. doi: 10.1126/science.7545954

4. Futreal PA, Liu Q, Shattuck-Eidens D, Cochran C, Harshman K, Tavtigian S, et al. BRCA1 mutations in primary breast and ovarian carcinomas. Science. (1994) 266:120-2. doi: 10.1126/science.7939630

5. Wooster R, Neuhausen SL, Mangion J, Quirk Y, Ford D, Collins N, et al. Localization of a breast cancer susceptibility gene, BRCA2, to chromosome 13q12-13. Science. (1994) 265:2088-90. doi: 10.1126/science.8091231

6. Wooster R, Bignell G, Lancaster J, Swift S, Seal S, Mangion J, et al. Identification of the breast cancer susceptibility gene BRCA2. Nature. (1995) 378:789-92. doi: 10.1038/378789a0

7. Chapman JR, Taylor MRG, Boulton SJ. Playing the end game: DNA doublestrand break repair pathway choice. Mol Cell. (2012) 47:497-510. doi: 10. 1016/j.molcel.2012.07.029

8. Venkitaraman AR. Cancer susceptibility and the functions of BRCA1 and BRCA2. Cell. (2002) 108:171-82. doi: 10.1016/s0092-8674(02)00615-3

9. Stoppa-Lyonnet D. The biological effects and clinical implications of BRCA mutations: where do we go from here? Eur J Hum Genet. (2016) 24(Suppl. 1):S3-9. doi: 10.1038/ejhg.2016.93

10. Easton DF, Ford D, Bishop DT. Breast and ovarian cancer incidence in BRCA1-mutation carriers. Breast cancer linkage consortium. Am J Hum Genet. (1995) 56:265-71.

11. Struewing JP, Hartge P, Wacholder S, Baker SM, Berlin M, McAdams M, et al. The risk of cancer associated with specific mutations of BRCA1 and BRCA2 among Ashkenazi Jews. N Engl J Med. (1997) 336:1401-8. doi: 10. 1056/NEJM199705153362001

12. Antoniou A, Pharoah PDP, Narod S, Risch HA, Eyfjord JE, Hopper JL, et al. Average risks of breast and ovarian cancer associated with BRCA1 or BRCA2 mutations detected in case series unselected for family history: a combined analysis of 22 studies. Am J Hum Genet. (2003) 72:1117-30. doi: $10.1086 / 375033$

13. Chen S, Parmigiani G. Meta-analysis of BRCA1 and BRCA2 penetrance. $J$ Clin Oncol. (2007) 25:1329-33. doi: 10.1200/JCO.2006.09.1066

14. Mavaddat N, Peock S, Frost D, Ellis S, Platte R, Fineberg E, et al. Cancer risks for BRCA1 and BRCA2 mutation carriers: results from prospective analysis of EMBRACE. J Natl Cancer Inst. (2013) 105:812-22. doi: 10.1093/jnci/djt095

15. Antoniou AC, Casadei S, Heikkinen T, Barrowdale D, Pylkäs K, Roberts J, et al. Breast-cancer risk in families with mutations in PALB2. $N$ Engl J Med. (2014) 371:497-506. doi: 10.1056/NEJMoa1400382

16. Evans MK, Longo DL. PALB2 mutations and breast-cancer risk. N Engl J Med. (2014) 371:566-8. doi: 10.1056/nejme1405784

17. Ramus SJ, Song H, Dicks E, Tyrer JP, Rosenthal AN, Intermaggio MP, et al. Germline mutations in the BRIP1, BARD1, PALB2, and NBN genes in women with ovarian cancer. J Natl Cancer Inst. (2015) 107:djv214. doi: 10.1093/jnci/djv214

18. Song H, Dicks E, Ramus SJ, Tyrer JP, Intermaggio MP, Hayward J, et al. Contribution of germline mutations in the RAD51B, RAD51C, and RAD51D genes to ovarian cancer in the population. J Clin Oncol. (2015) 33:2901-7. doi: 10.1200/JCO.2015.61.2408

\section{AUTHOR CONTRIBUTIONS}

$\mathrm{AH}$ and GT contributed equally to the conception, initial drafting, and final editing of this review article. Both authors approved the submitted version.

19. Cancer Genome Atlas Research Network. Integrated genomic analyses of ovarian carcinoma. Nature. (2011) 474:609-15. doi: 10.1038/nature 10166

20. Walsh T, Casadei S, Lee MK, Pennil CC, Nord AS, Thornton AM, et al. Mutations in 12 genes for inherited ovarian, fallopian tube, and peritoneal carcinoma identified by massively parallel sequencing. Proc Natl Acad Sci USA. (2011) 108:18032-7. doi: 10.1073/pnas.1115052108

21. Weber-Lassalle N, Hauke J, Ramser J, Richters L, Groß E, Blümcke B, et al. BRIP1 loss-of-function mutations confer high risk for familial ovarian cancer, but not familial breast cancer. Breast Cancer Res. (2018) 20:7. doi: 10.1186/ s13058-018-0935-9

22. Suszynska M, Kluzniak W, Wokolorczyk D, Jakubowska A, Huzarski T, Gronwald J, et al. BARD1 is a low/moderate breast cancer risk gene: evidence based on an association study of the Central European p.Q564X recurrent mutation. Cancers (Basel). (2019) 11:740. doi: 10.3390/cancers11060740

23. Walsh T, King M-C. Ten genes for inherited breast cancer. Cancer Cell. (2007) 11:103-5. doi: 10.1016/j.ccr.2007.01.010

24. Loveday C, Turnbull C, Ramsay E, Hughes D, Ruark E, Frankum JR, et al. Germline mutations in RAD51D confer susceptibility to ovarian cancer. Nat Genet. (2011) 43:879-82. doi: 10.1038/ng.893

25. Domchek SM, Robson ME. Update on genetic testing in gynecologic cancer. J Clin Oncol. (2019) 37:2501-9. doi: 10.1200/jco.19.00363

26. NCCN Guidelines. National Comprehensive Cancer Network Web Site. (2020). Available online at: https://www.nccn.org/professionals/physician_ gls/default.aspx (accessed Jul 26, 2020)

27. Krammer J, Pinker-Domenig K, Robson ME, Gonen M, Bernard-Davila B, Morris EA, et al. Breast cancer detection and tumor characteristics in BRCA1 and BRCA2 mutation carriers. Breast Cancer Res Treat. (2017) 163:565-71. doi: 10.1007/s10549-017-4198-4

28. Pedersen L, Holck S, Mouridsen HT, Schødt T, Zedeler K. Prognostic comparison of three classifications for medullary carcinoma of the breast. Histopathology. (1999) 34:175-8. doi: 10.1046/j.1365-2559.1999. 00584.x

29. Ridolfi RL, Rosen PP, Port A, Kinne D, Miké V. Medullary carcinoma of the breast: a clinicopathologic study with 10 year follow-up. Cancer. (1977) 40:1365-85. doi: 10.1002/1097-0142(197710)40:4<1365:: aid-cncr2820400402>3.0.co;2-n

30. WHO Classification of Tumours Editorial Board. BRCA1/2-associated hereditary breast and ovarian cancer syndrome. 5th ed. Breast Tumours. Geneva: WHO (2019).

31. Perou CM, Sørlie T, Eisen MB, van de Rijn M, Jeffrey SS, Rees CA, et al. Molecular portraits of human breast tumours. Nature. (2000) 406:747-52. doi: $10.1038 / 35021093$

32. Mavaddat N, Barrowdale D, Andrulis IL, Domchek SM, Eccles D, Nevanlinna $\mathrm{H}$, et al. Pathology of breast and ovarian cancers among BRCA1 and BRCA2 mutation carriers: results from the consortium of investigators of modifiers of BRCA1/2 (CIMBA). Cancer Epidemiol Biomarkers Prev. (2012) 21:134-47. doi: 10.1158/1055-9965.EPI-11-0775

33. Lakhani SR, Manek S, Penault-Llorca F, Flanagan A, Arnout L, Merrett S, et al. Pathology of ovarian cancers in BRCA1 and BRCA2 carriers. Clin Cancer Res. (2004) 10:2473-81. doi: 10.1158/1078-0432.ccr-1029-3

34. Lee E, McKean-Cowdin R, Ma H, Spicer DV, Van Den Berg D, Bernstein L, et al. Characteristics of triple-negative breast cancer in patients with a BRCA1 mutation: results from a population-based study of young women. J Clin Oncol. (2011) 29:4373-80. doi: 10.1200/jco.2010.33.6446

35. Park B, Sohn JY, Yoon K-A, Lee KS, Cho EH, Lim MC, et al. Characteristics of BRCA1/2 mutations carriers including large genomic rearrangements in high risk breast cancer patients. Breast Cancer Res Treat. (2017) 163:139-50. doi: 10.1007/s10549-017-4142-7 
36. Breuer A, Kandel M, Fisseler-Eckhoff A, Sutter C, Schwaab E, Lück H-J, et al. BRCA1 germline mutation in a woman with metaplastic squamous cell breast cancer. Onkologie. (2007) 30:316-8. doi: 10.1159/000101515

37. Zhang Y, Lv F, Yang Y, Qian X, Lang R, Fan Y, et al. Clinicopathological features and prognosis of metaplastic breast carcinoma: experience of a major chinese cancer center. PLoS One. (2015) 10:e0131409. doi: 10.1371/journal. pone.0131409

38. Lakhani SR, Van De Vijver MJ, Jacquemier J, Anderson TJ, Osin PP, McGuffog L, et al. The pathology of familial breast cancer: predictive value of immunohistochemical markers estrogen receptor, progesterone receptor, HER-2, and p53 in patients with mutations in BRCA1 and BRCA2. J Clin Oncol. (2002) 20:2310-8. doi: 10.1200/jco.2002.09.023

39. Norquist BM, Harrell MI, Brady MF, Walsh T, Lee MK, Gulsuner S, et al. Inherited mutations in women with ovarian carcinoma. JAMA Oncol. (2016) 2:482-90. doi: 10.1001/jamaoncol.2015.5495

40. Schrader KA, Hurlburt J, Kalloger SE, Hansford S, Young S, Huntsman DG, et al. Germline BRCA1 and BRCA2 mutations in ovarian cancer: utility of a histology-based referral strategy. Obstet Gynecol. (2012) 120(Pt 1):235-40. doi: 10.1097/aog.0b013e31825f3576

41. Shaw PA, McLaughlin JR, Zweemer RP, Narod SA, Risch H, Verheijen RHM, et al. Histopathologic features of genetically determined ovarian cancer. Int $J$ Gynecol Pathol. (2002) 21:407-11. doi: 10.1097/00004347-200210000-00011

42. Soslow RA, Han G, Park KJ, Garg K, Olvera N, Spriggs DR, et al. Morphologic patterns associated with BRCA1 and BRCA2 genotype in ovarian carcinoma. Mod Pathol. (2012) 25:625-36. doi: 10.1038/modpathol.2011.183

43. Pal T, Permuth-Wey J, Kumar A, Sellers TA. Systematic review and metaanalysis of ovarian cancers: estimation of microsatellite-high frequency and characterization of mismatch repair deficient tumor histology. Clin Cancer Res. (2008) 14:6847-54. doi: 10.1158/1078-0432.ccr-08-1387

44. King M-C, Marks JH, Mandell JB. New York Breast Cancer study group. Breast and ovarian cancer risks due to inherited mutations in BRCA1 and BRCA2. Science. (2003) 302:643-6. doi: 10.1126/science.1088759

45. McAlpine JN, Porter H, Köbel M, Nelson BH, Prentice LM, Kalloger SE, et al. BRCA1 and BRCA2 mutations correlate with TP53 abnormalities and presence of immune cell infiltrates in ovarian high-grade serous carcinoma. Mod Pathol. (2012) 25:740-50. doi: 10.1038/modpathol.2011.211

46. Alsop K, Fereday S, Meldrum C, deFazio A, Emmanuel C, George J, et al. BRCA mutation frequency and patterns of treatment response in BRCA mutation-positive women with ovarian cancer: a report from the australian ovarian cancer study group. J Clin Oncol. (2012) 30:2654-63. doi: 10.1200/ jco.2011.39.8545

47. Pennington KP, Walsh T, Harrell MI, Lee MK, Pennil CC, Rendi MH, et al. Germline and somatic mutations in homologous recombination genes predict platinum response and survival in ovarian, fallopian tube, and peritoneal carcinomas. Clin Cancer Res. (2014) 20:764-75. doi: 10.1158/ 1078-0432.ccr-13-2287

48. Hoang LN, Gilks BC. Hereditary breast and ovarian cancer syndrome: moving beyond BRCA1 and BRCA2. Adv Anat Pathol. (2018) 25:85-95. doi: 10.1097/pap.0000000000000177

49. Fujiwara M, McGuire V, Felberg A, Sieh W, Whittemore AS, Longacre TA. Prediction of BRCA1 germ line mutation status in women with Ovarian cancer using morphology-based criteria: identification of a BRCA1 Ovarian cancer phenotype. Am J Surg Pathol. (2012) 36:1170-7. doi: 10.1097/pas. 0b013e31825d9b8d

50. Ritterhouse LL, Nowak JA, Strickland KC, Garcia EP, Jia Y, Lindeman NI, et al. Morphologic correlates of molecular alterations in extrauterine Müllerian carcinomas. Mod Pathol. (2016) 29:893-903. doi: 10.1038/ modpathol.2016.82

51. Reyes MC, Arnold AG, Kauff ND, Levine DA, Soslow RA. Invasion patterns of metastatic high-grade serous carcinoma of ovary or fallopian tube associated with BRCA deficiency. Mod Pathol. (2014) 27:1405-11. doi: 10. 1038/modpathol.2013.237

52. Hussein YR, Ducie JA, Arnold AG, Kauff ND, Vargas-Alvarez HA, Sala E, et al. Invasion patterns of metastatic extrauterine high grade serous carcinoma with BRCA germline mutation and correlation with clinical outcomes. Am J Surg Pathol. (2016) 40:404-9. doi: 10.1097/pas. 0000000000000556

53. Kommoss F, Kommoss S, Schmidt D, Trunk MJ, Pfisterer J, du Bois A, et al. Survival benefit for patients with advanced-stage transitional cell carcinomas vs. other subtypes of ovarian carcinoma after chemotherapy with platinum and paclitaxel. Gynecol Oncol. (2005) 97:195-9. doi: 10.1016/j.ygyno.2004. 12.047

54. Garg K, Levine DA, Olvera N, Dao F, Bisogna M, Secord AA, et al. BRCA1 immunohistochemistry in a molecularly characterized cohort of ovarian high-grade serous carcinomas. Am J Surg Pathol. (2013) 37:138-46. doi: $10.1097 /$ pas.0b013e31826cabbd

55. Meisel JL, Hyman DM, Garg K, Zhou Q, Dao F, Bisogna M, et al. The performance of BRCA1 immunohistochemistry for detecting germline, somatic, and epigenetic BRCA1 loss in high-grade serous ovarian cancer. Ann Oncol. (2014) 25:2372-8. doi: 10.1093/annonc/mdu461

56. Kashima K, Oite T, Aoki Y, Takakuwa K, Aida H, Nagata H, et al. Screening of BRCA1 mutation using immunohistochemical staining with $\mathrm{C}$-terminal and $\mathrm{N}$-terminal antibodies in familial ovarian cancers. Jpn J Cancer Res. (2000) 91:399-409. doi: 10.1111/j.1349-7006.2000.tb00959.x

57. Teixeira LA, Candido Dos Reis FJ. Immunohistochemistry for the detection of BRCA1 and BRCA2 proteins in patients with ovarian cancer: a systematic review. J Clin Pathol. (2019) 73:191-6. doi: 10.1136/jclinpath-2019206276

58. Piek JM, van Diest PJ, Zweemer RP, Jansen JW, Poort-Keesom RJ, Menko FH, et al. Dysplastic changes in prophylactically removed Fallopian tubes of women predisposed to developing ovarian cancer. J Pathol. (2001) 195:451-6. doi: $10.1002 /$ path. 1000

59. Soong TR, Howitt BE, Miron A, Horowitz NS, Campbell F, Feltmate CM, et al. Evidence for lineage continuity between early serous proliferations (ESPs) in the Fallopian tube and disseminated high-grade serous carcinomas. J Pathol. (2018) 246:344-51. doi: 10.1002/path.5145

60. Medeiros F, Muto MG, Lee Y, Elvin JA, Callahan MJ, Feltmate C, et al. The tubal fimbria is a preferred site for early adenocarcinoma in women with familial ovarian cancer syndrome. Am J Surg Pathol. (2006) 30:230-6. doi: 10.1097/01.pas.0000180854.28831.77

61. Mehrad M, Ning G, Chen EY, Mehra KK, Crum CP. A pathologist's road map to benign, precancerous, and malignant intraepithelial proliferations in the fallopian tube. Adv Anat Pathol. (2010) 17:293-302. doi: 10.1097/pap. 0b013e3181ecdee1

62. Jarboe E, Folkins A, Nucci MR, Kindelberger D, Drapkin R, Miron A, et al. Serous carcinogenesis in the fallopian tube: a descriptive classification. Int J Gynecol Pathol. (2008) 27:1-9. doi: 10.1097/pgp.0b013e31814b191f

63. Przybycin CG, Kurman RJ, Ronnett BM, Shih I-M, Vang R. Are all pelvic (nonuterine) serous carcinomas of tubal origin? Am J Surg Pathol. (2010) 34:1407-16. doi: 10.1097/pas.0b013e3181ef7b16

64. Kindelberger DW, Lee Y, Miron A, Hirsch MS, Feltmate C, Medeiros F, et al. Intraepithelial carcinoma of the fimbria and pelvic serous carcinoma: Evidence for a causal relationship. Am J Surg Pathol. (2007) 31:161-9. doi: 10.1097/01.pas.0000213335.40358.47

65. Colgan TJ, Murphy J, Cole DE, Narod S, Rosen B. Occult carcinoma in prophylactic oophorectomy specimens: prevalence and association with BRCA germline mutation status. Am J Surg Pathol. (2001) 25:1283-9. doi: 10.1097/00000478-200110000-00009

66. Gilbert L, Basso O, Sampalis J, Karp I, Martins C, Feng J, et al. Assessment of symptomatic women for early diagnosis of ovarian cancer: results from the prospective DOvE pilot project. Lancet Oncol. (2012) 13:285-91. doi: 10.1016/s1470-2045(11)70333-3

67. SGO Guidelines. Society of Gynecologic Oncology web site. Chicago, IL: SGO (2020).

68. Ghezelayagh TS, Stewart LE, Norquist BM, Bowen DJ, Yu V, Agnew KJ, et al. Perceptions of risk and reward in BRCA1 and BRCA2 mutation carriers choosing salpingectomy for ovarian cancer prevention. Fam Cancer. (2020) 19:143-51. doi: 10.1007/s10689-020-00166-5

69. Visvanathan K, Vang R, Shaw P, Gross A, Soslow R, Parkash V, et al. Diagnosis of serous tubal intraepithelial carcinoma based on morphologic and immunohistochemical features: a reproducibility study. Am J Surg Pathol. (2011) 35:1766-75. doi: 10.1097/pas.0b013e31822f58bc

70. Vang R, Visvanathan K, Gross A, Maambo E, Gupta M, Kuhn E, et al. Validation of an algorithm for the diagnosis of serous tubal intraepithelial carcinoma. Int J Gynecol Pathol. (2012) 31:243-53. doi: 10.1097/PGP. 0b013e31823b8831

71. Kuhn E, Kurman RJ, Vang R, Sehdev AS, Han G, Soslow R, et al. TP53 mutations in serous tubal intraepithelial carcinoma and concurrent pelvic 
high-grade serous carcinoma-evidence supporting the clonal relationship of the two lesions. J Pathol. (2012) 226:421-6. doi: 10.1002/path.3023

72. Lee Y, Miron A, Drapkin R, Nucci MR, Medeiros F, Saleemuddin A, et al. A candidate precursor to serous carcinoma that originates in the distal fallopian tube. J Pathol. (2007) 211:26-35. doi: 10.1002/path.2091

73. Meserve EEK, Brouwer J, Crum CP. Serous tubal intraepithelial neoplasia: the concept and its application. Mod Pathol. (2017) 30:710-21. doi: 10.1038/ modpathol.2016.238

74. Roh MH, Yassin Y, Miron A, Mehra KK, Mehrad M, Monte NM, et al. Highgrade fimbrial-ovarian carcinomas are unified by altered p53, PTEN and PAX2 expression. Mod Pathol. (2010) 23:1316-24. doi: 10.1038/modpathol. 2010.119

75. Howitt BE, Hanamornroongruang S, Lin DI, Conner JE, Schulte S, Horowitz $\mathrm{N}$, et al. Evidence for a dualistic model of high-grade serous carcinoma: BRCA mutation status, histology, and tubal intraepithelial carcinoma. Am J Surg Pathol. (2015) 39:287-93. doi: 10.1097/pas.0000000000000369

76. Soong TR, Howitt BE, Horowitz N, Nucci MR, Crum CP. The fallopian tube, "precursor escape" and narrowing the knowledge gap to the origins of high-grade serous carcinoma. Gynecol Oncol. (2019) 152:426-33. doi: 10.1016/j.ygyno.2018.11.033

77. Singh N, Gilks CB, Hirshowitz L, Wilkinson N, McCluggage WG. Adopting a uniform approach to site assignment in tubo-ovarian high-grade serous carcinoma: the time has come. Int J Gynecol Pathol. (2016) 35:230-7. doi: 10.1097/pgp.0000000000000270

78. de Jonge MM, Auguste A, van Wijk LM, Schouten PC, Meijers M, Ter Haar NT, et al. Frequent homologous recombination deficiency in highgrade endometrial carcinomas. Clin Cancer Res. (2019) 25:1087-97. doi: 10.1158/1078-0432.ccr-18-1443

79. de Jonge MM, Ritterhouse LL, de Kroon CD, Vreeswijk MPG, Segal JP, Puranik R, et al. Germline BRCA-associated endometrial carcinoma is a distinct clinicopathologic entity. Clin Cancer Res. (2019) 25:7517-26. doi: 10.1158/1078-0432.ccr-19-0848

80. Friedenson B. BRCA1 and BRCA2 pathways and the risk of cancers other than breast or ovarian. Medscape Gen Med. (2005) 7:60.

81. Moran A, O'Hara C, Khan S, Shack L, Woodward E, Maher ER, et al. Risk of cancer other than breast or ovarian in individuals with BRCA1 and BRCA2 mutations. Fam Cancer. (2012) 11:235-42. doi: 10.1007/s10689-011-9506-2

82. Gumaste PV, Penn LA, Cymerman RM, Kirchhoff T, Polsky D, McLellan B. Skin cancer risk in BRCA1/2 mutation carriers. Br J Dermatol. (2015) 172:1498-506. doi: 10.1111/bjd.13626

83. Yang SYC, Lheureux S, Karakasis K, Burnier JV, Bruce JP, Clouthier DL, et al. Landscape of genomic alterations in high-grade serous ovarian cancer from exceptional long- and short-term survivors. Genome Med. (2018) 10:81. doi: 10.1186/s13073-018-0590-x

84. Telli ML, Hellyer J, Audeh W, Jensen KC, Bose S, Timms KM, et al. Homologous recombination deficiency (HRD) status predicts response to standard neoadjuvant chemotherapy in patients with triple-negative or BRCA1/2 mutation-associated breast cancer. Breast Cancer Res Treat. (2018) 168:625-30. doi: 10.1007/s10549-017-4624-7

85. Graeser M, McCarthy A, Lord CJ, Savage K, Hills M, Salter J, et al. A marker of homologous recombination predicts pathologic complete response to neoadjuvant chemotherapy in primary breast cancer. Clin Cancer Res. (2010) 16:6159-68. doi: 10.1158/1078-0432.ccr-10-1027

86. Baretta Z, Mocellin S, Goldin E, Olopade OI, Huo D. Effect of BRCA germline mutations on breast cancer prognosis: a systematic review and meta-analysis. Medicine (Baltimore). (2016) 95:e4975. doi: 10.1097/md.0000000000004975

87. Heale JT, Ball AR, Schmiesing JA, Kim J-S, Kong X, Zhou S, et al. Condensin I interacts with the PARP-1-XRCC1 complex and functions in DNA singlestrand break repair. Mol Cell. (2006) 21:837-48. doi: 10.1016/j.molcel.2006. 01.036

88. Sisay M, Edessa D. PARP inhibitors as potential therapeutic agents for various cancers: focus on niraparib and its first global approval for maintenance therapy of gynecologic cancers. Gynecol Oncol Res Pract. (2017) 4:18. doi: 10.1186/s40661-017-0055-8

89. Strickland KC, Howitt BE, Shukla SA, Rodig S, Ritterhouse LL, Liu JF, et al. Association and prognostic significance of BRCA1/2-mutation status with neoantigen load, number of tumor-infiltrating lymphocytes and expression of PD-1/PD-L1 in high grade serous ovarian cancer. Oncotarget. (2016) 7:13587-98. doi: 10.18632/oncotarget.7277
90. Darb-Esfahani S, Kunze CA, Kulbe H, Sehouli J, Wienert S, Lindner J, et al. Prognostic impact of programmed cell death-1 (PD-1) and PD-ligand 1 (PDL1) expression in cancer cells and tumor-infiltrating lymphocytes in ovarian high grade serous carcinoma. Oncotarget. (2016) 7:1486-99. doi: 10.18632/ oncotarget.6429

91. Wen WX, Leong C-O. Association of BRCA1- and BRCA2-deficiency with mutation burden, expression of PD-L1/PD-1, immune infiltrates, and T cellinflamed signature in breast cancer. PLoS One. (2019) 14:e0215381. doi: 10.1371/journal.pone.0215381

92. Forbes C, Fayter D, de Kock S, Quek RG. A systematic review of international guidelines and recommendations for the genetic screening, diagnosis, genetic counseling, and treatment of BRCA-mutated breast cancer. Cancer Manag Res. (2019) 11:2321-37. doi: 10.2147/cmar.s189627

93. Neff RT, Senter L, Salani R. BRCA mutation in ovarian cancer: testing, implications and treatment considerations. Ther Adv Med Oncol. (2017) 9:519-31. doi: 10.1177/1758834017714993

94. Pal T, Permuth-Wey J, Betts JA, Krischer JP, Fiorica J, Arango H, et al. BRCA1 and BRCA2 mutations account for a large proportion of ovarian carcinoma cases. Cancer. (2005) 104:2807-16. doi: 10.1002/cncr. 21536

95. Grindedal EM, Heramb C, Karsrud I, Ariansen SL, Mæhle L, Undlien DE, et al. Current guidelines for BRCA testing of breast cancer patients are insufficient to detect all mutation carriers. BMC Cancer. (2017) 17:438. doi: 10.1186/s12885-017-3422-2

96. American College of Obstetricians and Gynecologists, ACOG Committee on Practice Bulletins-Gynecology, ACOG Committee on Genetics, Society of Gynecologic Oncologists. ACOG Practice Bulletin No. 103: hereditary breast and ovarian cancer syndrome. Obstet Gynecol. (2009) 113:957-66. doi: 10.1097/aog.0b013e3181a106d4

97. Hampel H, Bennett RL, Buchanan A, Pearlman R, Wiesner GL, Guideline Development Group, et al. A practice guideline from the American College of Medical Genetics and Genomics and the National Society of Genetic Counselors: referral indications for cancer predisposition assessment. Genet Med. (2015) 17:70-87. doi: 10.1038/gim.2014.147

98. Lancaster JM, Powell CB, Chen L-M, Richardson DL, Sgo Clinical Practice Committee. Society of Gynecologic Oncology statement on risk assessment for inherited gynecologic cancer predispositions. Gynecol Oncol. (2015) 136:3-7. doi: 10.1016/j.ygyno.2014.09.009

99. Randall LM, Pothuri B, Swisher EM, Diaz JP, Buchanan A, Witkop CT, et al. Multi-disciplinary summit on genetics services for women with gynecologic cancers: a society of gynecologic oncology white paper. Gynecol Oncol. (2017) 146:217-24. doi: 10.1016/j.ygyno.2017.06.002

100. McCuaig JM, Stockley TL, Shaw P, Fung-Kee-Fung M, Altman AD, Bentley $\mathrm{J}$, et al. Evolution of genetic assessment for BRCA-associated gynaecologic malignancies: a Canadian multisociety roadmap. J Med Genet. (2018) 55:5717. doi: 10.1136/jmedgenet-2018-105472

101. Hooker GW, Clemens KR, Quillin J, Vogel Postula KJ, Summerour P, Nagy R, et al. Cancer genetic counseling and testing in an Era of rapid change. J Genet Couns. (2017) 26:1244-53. doi: 10.1007/s10897-0170099-2

102. Marcus RK, Geurts JL, Grzybowski JA, Turaga KK, Clark Gamblin T, Strong KA, et al. Challenges to clinical utilization of hereditary cancer gene panel testing: perspectives from the front lines. Fam Cancer. (2015) 14:641-9. doi: 10.1007/s10689-015-9817-9

103. Bartosch C, Clarke B, Bosse T. Gynaecological neoplasms in common familial syndromes (Lynch and HBOC). Pathology (Phila). (2018) 50:222-37. doi: 10.1016/j.pathol.2017.10.010

Conflict of Interest: The authors declare that the research was conducted in the absence of any commercial or financial relationships that could be construed as a potential conflict of interest.

Copyright $\odot 2020$ Hodgson and Turashvili. This is an open-access article distributed under the terms of the Creative Commons Attribution License (CC BY). The use, distribution or reproduction in other forums is permitted, provided the original author(s) and the copyright owner(s) are credited and that the original publication in this journal is cited, in accordance with accepted academic practice. No use, distribution or reproduction is permitted which does not comply with these terms. 